\title{
PENGARUH BAURAN PEMASARAN (MARKETING MIX) TERHADAP LOYALITAS KONSUMEN PADA RESTORAN CEPAT SAJI O'CHICKEN DI PEKANBARU
}

\author{
Yusriadi \\ Sekolah Tinggi Ilmu Ekonomi Riau \\ Jln. H.R. Subrantas KM 10,5 Panam, Pekanbaru \\ E-mail : yusriadi76@gmail.com
}

\begin{abstract}
Marketing mix is a combination of several methods to promote the product so as to achieve maximum results with minimum costs include market research, product strategy, promotion, pricing and distribution. Customer loyaltyis the result to be tained froman organization that creates benefits to its customers, so they will still make purchase sand even increase the purchase of the organization, creating real consumer loyalty when the customer be comes an advocate for the company even without the incentive. This research is meant to analyze and to test the influence of product, price, promotion and place to the customer loyalty at Fast food restaurant of O-Chicken Pekanbaru. The sample collection technique has been done by using purposive sampling and the data analysis technique has been done by using multiple linear regressions and the samples are 32 people. The result of this research shows that product and promotion has positive and significant impact on customer loyalty. While price and place not impact and not significant on customer loyalty
\end{abstract}

Keywords: Product, Price, Promotion, Place and Customer Loyalty

\section{PENDAHULUAN}

Dalam lingkungan persaingan bisnis yang semakin ketat dan siklus produk yang semakin pendek, pelaku usaha di tuntut memiliki strategi yang mampu berdaya saing. Kemampuan berdaya saing akan berdampak terhadap meningkatnya jumlah pelanggan sehingga perusahaan dapat terus survive dimana life time perusahaan semakin lebih lama. Salah satu strategi menumbuh kembangkan suatu bisnis adalah dengan sistem waralaba (franchise).

Pertumbuhan usaha waralaba (franchise) kini semakin berkembang di Indonesia. Keberadaan waralaba yang semakin marak beberapa tahun terakhir ini tidak mungkin dihindari lagi. Waralaba merupakan strategi yang efektif untuk mengembangkan jaringan bisnis dengan tidak menghilangkan karakter perusahaan yang sudah menjadi ciri khas waralaba yang bersangkutan.
Pertumbuhan dan perkembangan usaha waralaba di kota Pekanbaru di provinsi Riau juga saat ini begitu pesat. Hal ini ditandai dengan berdirinya usahausaha baru yang bergerak dibidang penyediaan pangan dalam bentuk waralaba seperti Mc Donald, Kentucky Fried Chicken (KFC), Texas, A\&W Restaurant dan sebagainya. Perusahaan cepat saji ini selalu berkembang pesat setiap tahunnya dengan jumlah pelanggan yang semakin banyak. Salah satu pemain baru dalam bisnis waralaba restoran cepat saji adalah O'Chicken.

O'Chicken merupakan sebuah usaha yang saat ini bergerak dalam bidang makanan atau kuliner berbentuk franchise. Usaha ini merupakan kuliner yang menyajikan ayam goreng yang organik, bebas bahan-bahan kimia. Ayam organik disebut juga ayam herbal atau ayam probiotik. Ayam organik merupakan ayam broiler atau ayam potong yang dibudidaya dari saat setelah menetas hingga panen dengan menggunakan pakan 


\section{Jurnal Ilmiah Ekonomi dan Bisnis}

Vol. 15. No.1, Maret 2018: 71-77

EISSN : $2442-9813$

ISSN : 1829-9822

khusus yakni jagung, dedak, tepung ikan, dan lain-lain serta tambahan jamu ternak berupa ramuan herbal sebagai probiotik alami pengganti antibiotik dan anti stress kimia yang biasa digunakan dalam peternakan ayam broiler pada biasanya.

Sebagai pemain baru dalam bisnis waralaba, penting bagi O-Chicken meningkatkan penjualan dan menghadapi para pesaingnya dengan menerapkan strategi bauran pemasaran (marketing mix). Bauran pemasaran merupakan seperangkat alat pemasaran yang digunakan pemasar untuk terusmenerus mencapai tujuan pemasarannya di pasar sasaran (Kotler, 2009). Bauran pemasaran meliputi produk (product), harga (price), promosi (promotion) dan tempat (place), yang perlu dilakukan dan dipahami dengan baik oleh perusahaan agar tetap bisa berkembang di dalam persaingan yang sangat ketat.

Beberapa strategi yang termasuk 4P dalam bauran dapat diuraikan lagi secara lebih spesifik untuk setiap $\mathrm{P}$ tersebut (Kotler, 2009) menguraikan di bidang product, pemasar akan merancang produknya agar memiliki kualitas yang baik, bentuk yang unik, ukuran yang sesuai dengan kebutuhan konsumen, warna yang menarik, rasa yang sesuai dengan keinginan konsumen, serta hal-hal lain yang termasuk dalam strategi produk. Di bidang price, pemasar bisa merancang strategi harga yang murah, harga yang wajar, atau harga premium. Selanjutnya di bidang di bidang promotion pemasar harus menemukan pola komunikasi yang tepat sesuai dengan segmentasi pasar sasarannya. Sedangkan pada bidang place, pemasar harus mendapatkan lokasi yang strategis, mudah dijangkau, lokasi yang unik serta nyaman.

Beberapa penelitian terdahulu yang dilakukan Kurniawati (2014) menyatakan bahwa bauran pemasaran mempengaruhi loyalitas pelanggan dalam menggunakan suatu produk. Yonaldi (2011) menyatakan bahwa kewajaran harga berpengaruh terhadap loyalitas konsumen produk minuman teh botol sosro frestea di Padang, serta penelitian yang dilakukan oleh Wirasti (2010) dan Mei (2012) menyatakan bahwa semakin harga yang ditetapkan sesuai dengan kualitas produk maka dapat meningkatkan rasa loyalitas konsumen terhadap suatu barang. Oetama (2011) dalam penelitiannya juga meyebutkan promosi yang baik dapat mempengaruhi loyalitas konsumen saat sudah menggunakan produk. Hasil penelitian yang dilakukan Risyamuka (2013) serta Lumintang (2013) menyatakan bahwa lokasi yang strategis dan mudah dijangkau oleh konsumen akan dapat mempertahankan loyalitas dari konsumen.

Konsumen merasa loyal terhadap produk tentunya dengan cara mempertimbangkan atribut atribut marketing mix yang diberikan oleh perusahaan (Griffin, 2006). Loyalitas pelanggan akan berlanjut hanya sepanjang konsumen merasakan telah menerima suatu nilai yang lebih baik termasuk kualitas yang lebih tinggi dibandingkan ke penyedia barang/jasa lain.

\section{TINJAUAN PUSTAKA}

Pemasaran adalah proses sosial yang didalamnya individu dan kelompok mendapatkan apa yang mereka butuhkan dan inginkan dengan menciptakan, menawarkan dan secara bebas mempertukarkan produk yang bernilai dengan pihak lain. Kotler (2008) menyatakan bahwa pemasaran adalah suatu sistem keseluruhan dari kegiatankegiatan bisnis yang ditujukan untuk merencanakan, menentukan harga, mempromosikan dan mendistribusikan barang dan jasa yang memuaskan kebutuhan baik kepada pembeli yang ada maupun pembeli potensial.

Menurut Kotler dan Armstrong (2011), pemasaran adalah segala kegiatan 
untuk menyampaikan barang-barang ke tangan (rumah tangga) dan ke konsumen industri, tetapi tidak termasuk kegiatan perubahan bentuk barang. Pengertian pemasaran dari pendapat di atas menerangkan bahwa kegiatan pemasaran mencakup ruang lingkup kegiatan yang sangat luas yang dimulai dari menetukan kebutuhan konsumen dan diakhiri dengan kepuasan konsumen. Dengan kata lain kegiatan pemasaran bermula dan berakhir pada konsumen.

Dalam bauran pemasaran (marketing mix) terdapat variabelvariabel yang saling mendukung satu dengan yang lainnya yang kemudian oleh perusahaan digabungkan untuk memperoleh tanggapan-tanggapan yang diinginkan didalam pasar sasaran.

Marketing mix atau bauran pemasaran adalah kombinasi dari empat variabel yaitu produk, struktur harga, kegiatan promosi, dan sistem distribusi (Fandy Tjipto (2011) mermuskan bauran pemasaran menjadi 4P (Product, Price, Place dan Promotion).

Menurut Philip Kotler dalam Danang Sunyoto (2014) produk adalah sesuatu yang dapat ditawarkan ke pasar untuk di perhatikan, diminta, dipakai, dikosumsi sehingga dapat memuaskan keinginan atau kebutuhan termasuk didalamnya adalah objek fisik, jasa, orang, tempat organisasi dan gagasan."

Menurut Indriyo Gitosudarmo dalam Danang Sunyoto (2014) harga adalah nilai yang dinyatakan dalam satu mata uang atau alat tukar, terhadap suatu produk tertentu. Dalam kenyataannya besar dan kecilnya nilai atau harga itu tidak hanya di tentukan oleh factor fisik saja yang di perhitungkan tetapi factorfaktor psikologis dan factor lainnya berpengaruh terhadap harga.

Promosi adalah suatu bentuk komunikasi pemasaran yang merupakan aktivitas pemasaran yang berusaha menyebarkan informasi, mempengaruhi/ membujuk, dan/ atau meningatkan pasar sasaran atas perusahaan dan produknya agar bersedia menerima, membeli, dan loyal pada produk yang ditawarkan perusahaan yang bersangkutan. Tjiptono (2011)

Lokasi atau tempat seringkali ikut menentukan kesuksesan perusahaan, karena lokasi erat kaitannya dengan pasar potensial sebuah perusahaan. Disamping itu, lokasi juga berpengaruh terhadap dimensi-dimensi strategi seperti flexibility, competitive, positioning, dan focus. Fleksibelitas suatu lokasi merupakan ukuran sejauh mana suatu perusahaan dapat bereaksi terhadap perubahan situasi ekonomi. Keputusan pemilihan lokasi berkaitan dengan komitmen jangka panjang terhadap aspekaspek yang sifatnya kapital intensif, maka perusahaan benar-benar harus mempertimbangkan dan menyeleksi lokasi yang responsif terhadap situasi ekonomi, demografi, budaya, dan persaingan di masa mendatang. Tjiptono (2011).

Hurriyati (2010) mengemukakan loyalitas pelanggan adalah komitmen pelanggan bertahan secara mendalam untuk berlangganan kembali atau melakukan pembelian ulang produk/jasa terpilih secara konsisten di masa yang akan datang, meskipun pengaruh situasi dan usaha-usaha pemasaran mempunyai potensi untuk menyebabkan perubahan perilaku.

Griffin (2009) berpendapat bahwa seorang pelanggan dikatakan setia atau loyal terhadap perusahaan apabila pelanggan tersebut menunjukkan indikator melakukan pembelian berulang secara teratur, membeli antarlini produk dan jasa, mereferensikan kepada orang lain dan menunjukkan kekebalan terhadap tarikan dari pesaing.

\section{METODE PENELITIAN}

Disain dalam penelitian ini merupakan penelitian deskriptif dan asosiatif (hubungan/pengaruh) yang 


\section{Jurnal Ilmiah Ekonomi dan Bisnis}

Vol. 15. No.1, Maret 2018: 71-77

EISSN : $2442-9813$

ISSN : $1829-9822$

bertujuan untuk mengetahui nilai masing-masing variable, baik satu atau lebih sifatnya independen tanpa membuat hubungan maupun perbandingan dengan variabel yang lain. Desain penelitian asosiatif adalah penelitian yang di desain untuk mengetahui pengaruh interaksi antara dua variabel atau lebih.

Populasi menurut Sugiyono (2010) adalah wilayah generalisasi yang terdiri atas obyek/subyek yang mempunyai kualitas dan karakteristik tertentu yang ditetapkan oleh peneliti untuk dipelajari dan kemudian ditarik kesimpulannya. Populasi dalam penelitian ini adalah seluruh masyarakat Pekanbaru yang pernah mengkonsumsi produk O'Chicken, karena jumlahnya tidak di ketahui secara pasti maka pengambilan sampel nya melalui metode sampling insidential. yakni teknik penentuan sampel secara kebetulan, atau siapa saja yang kebetulan (insidential) bertemu dengan peneliti yang dianggap cocok dengan karakteristik sampel yang ditentukan akan dijadikan sampel dengan jumlah 32 orang. Menurut Roscoe dan Uma Sekaran dalam Wiratna Sujarweni (2015) memberikan acuan umum untuk menentukan jumlah sampel adalah lebih dari 30 dan kurang dari 500 sudah tepat untuk kebanyakan penelitian.

Jenis dan sumber data yang digunakan dalam penelitian ini adalah sebagai berikut data kualitatif, yaitu data yang diperoleh dalam bentuk informasi, baik secara lisan maupun tulisan yang berkaitan dengan masalah yang diteliti. Data Kuantitatif, yaitu data yang diperoleh dalam bentuk angka-angka yang dapat dihitung, yang berkaitan dengan masalah yang diteliti. Dalam usaha memperoleh data yang dibutuhkan, metode yang digunakan adalah Studi kepustakaan (Library Research) yaitu yang dilakukan dengan membaca buku-buku dan majalah yang berhubungan dengan masalah yang diteliti, skripsi maupun thesis sebagai acuan penelitian terdahulu, dan dengan cara browsing di internet untuk mencari artikel-artikel serta jurnal-jurnal atau data-data yang dapat membantu hasil dari penelitian.

Dalam metode analisis data ini menggunakan analisis regresi linear berganda dengan spesifikasi model sebagai berikut :

$$
\begin{gathered}
\mathrm{Y}=\mathrm{a}+\mathrm{b}_{1} \mathrm{X}_{1}+\mathrm{b}_{2} \mathrm{X}_{2}+\mathrm{b}_{3} \mathrm{X}_{3}+\mathrm{b}_{4} \mathrm{X}_{4}+\mathrm{e} \\
\mathrm{Y}: \text { Variabel loyalitas konsumen } \\
a: \text { Konstanta } \\
\mathrm{X}_{1}: \text { Produk } \\
\mathrm{X}_{2}: \text { Harga } \\
\mathrm{X}_{3}: \text { Promosi } \\
\mathrm{X}_{4}: \text { Tempat } \\
b: \text { Koefisien regresi } \\
e: \text { Variabel pengganggu }
\end{gathered}
$$

\section{HASIL DAN PEMBAHASAN}

Hasil pengolahan analisis regresi berganda dengan menggunakan software SPSS 20 adalah sebagai berikut :

Persamaan regresi linear berganda dapat diperoleh berdasarkan tabel 4 dengan hasil sebagai berikut :

$\mathrm{Y}=\mathrm{a}+\mathrm{b}_{1} \mathrm{X}_{1}+\mathrm{b}_{2} \mathrm{X}_{2}+\mathrm{b}_{3} \mathrm{X}_{3}+\mathrm{b}_{4} \mathrm{X}_{4}+\mathrm{e}$ $\mathrm{Y}=-9,519+0,539+0,452+0,766+0,516+\mathrm{e}$

Dimana,

$\mathrm{Y}=$ Loyalitas Konsumen

$\mathrm{X}_{1}$ Produk : 0,539

$\mathrm{X}_{2}$ Harga $\quad: 0,452$

$\mathrm{X}_{3}$ Promosi : 0,766

$\mathrm{X}_{4}$ Tempat $: 0,516$

Koefisien determinasi $\left(\mathrm{R}^{2}\right)$ dalam output SPSS terletak pada tabel Model Summary $^{b}$ dan tertulis R.square berkisar Nol (0) sampai Satu (1) (Nugroho, 2005). Berikut tabel yang menunjukkan hasil pengujian determinasi.

Nilai koefisien determinasi yang di sesuaikan (Adjusted $R$ Square) sebesar 0,676 atau sebesar $67,6 \%$. Hal ini menunjukkan bahwa loyalitas konsumen dapat dijelaskan oleh produk, harga, promosi, dan tempat sebesar 67,6\% sedangkan sisanya sebesar $(100 \%-67,6$ 
$\%)=32,4 \%$ di jelaskan oleh faktor lainnya di luar dari variabel produk, harga, promosi, dan tempat (bauran pemasaran).

Uji statistik $F$ bertujuan untuk mengetahui apakah semua variabel independen yang dimasukkan dalam model mempunyai pengaruh secara bersama-sama terhadap variabel dependennya. Dalam tabel F angka 32 dengan tingkat signifikansi 0.05 adalah sebesar 3,29.

Hasil uji $\mathrm{F}$ hitung sebesar 17,189 $>\mathrm{F}$ Tabel $(3,29)$ dan signifikansi $\mathrm{F}$ sebesar $0,000<0,05$. Artinya nilai $F$ hitung lebih besar dari pada $\mathrm{F}$ tabel, dan nilai signifikan lebih kecil dari 0,05. Hasil ini dapat diartikan bahwa keempat variabel independen produk (X1), harga (X2) promosi (X3) dan tempat (X4) berpengaruh positif dan signifikan secara simultan terhadap loyalitas konsumen.

Untuk mengetahui variabel yang berpengaruh signifikan secara parsial dilakukan pengujian koefisien regresi dengan menggunakan statistik Uji t. Penentuan hasil pengujian (penerimaan/ penolakan $\mathrm{H}_{0}$ ) dapat dilakukan dengan membandingkan t-hitung dengan t-tabel atau juga dapat dilihat dari nilai signifikansinya. Adapun nilai t tabel dari penelitian ini adalah dengan tingkat signifikansi $5 \%$, adalah nilai df sebesar $(\mathrm{n}-\mathrm{k})$, dimana $\mathrm{n}=$ jumlah sampel dan $\mathrm{k}$ $=$ jumlah variabel, maka hasilnya $(32-5$ $=27$ ). Dalam $\mathrm{t}$ tabel angka 27 dengan tingkat signifikansi 0.05 adalah sebesar 2,051 .

Hasil pengujian parsial (uji t) antara variabel produk terhadap variabel loyalitas konsumen menunjukkan nilai $\mathrm{t}$ hitung sebesar 2,055 > t Tabel 2,051 dan nilai signifikansi sebesar $0,050{\text { maka } \mathrm{H}_{1}}$ diterima, hal ini berarti bahwa produk berpengaruh positif dan signifikan terhadap loyalitas konsumen. Berdasarkan hasil penelitian menunjukkan bahwa produk O'Chicken berupa besaran porsi ayam dan nasinya, kemasannya serta kualitas rasanya sudah sesuai dengan keinginan konsumen sehingga harus tetap di petahankan agar konsumen tetap loyal kepada O'Chicken.

Hasil pengujian parsial (uji t) antara variabel harga terhadap variabel loyalitas konsumen menunjukkan nilai $\mathrm{t}$ hitung sebesar 0,999 < t Tabel 2,051 dan nilai signifikansi sebesar $0,327>0,05$ maka $\mathrm{H}_{2}$ ditolak, artinya tidak terdapat pengaruh dan tidak signifikan antara harga terhadap loyalitas konsumen. Tidak adanya pengaruh harga terhadap loyalitas konsumen dalam penelitian ini menunjukkan harga yang di tawarkan pihak O'Chicken kepada konsumen masih di rasa mahal dan belum mampu bersaing dengan produk sejenis. Dengan demikian pihak O'Chicken harus kembali mempertimbangkan harga jual yang di tawarkan kepada pihak konsumen agar mendapatkan loyalitas konsumen melalui pendekatan harga jual produknya.

Hasil pengujian parsial (uji t) antara variabel promosi terhadap variabel loyalitas konsumen menunjukkan nilai $\mathrm{t}$ hitung sebesar 2,221>t Tabel 2,051 dan nilai signifikansi sebesar $0,035<0,050$ maka $\mathrm{H}_{3}$ diterima, hal ini berarti bahwa promosi berpengaruh positif dan signifikan terhadap loyalitas konsumen. Berdasarkan hasil penelitian menunjukkan bahwa kegiatan promosi O'Chicken dapat menjaga loyalitas konsumen.

Hasil pengujian parsial (uji t) antara variabel harga terhadap variabel loyalitas konsumen menunjukkan nilai $\mathrm{t}$ hitung sebesar 1,625 < t Tabel 2,051 dan nilai signifikansi sebesar $0,116>0,05$ maka $\mathrm{H}_{4}$ ditolak, artinya tidak terdapat pengaruh dan tidak signifikan antara tempat terhadap loyalitas konsumen. Tidak adanya pengaruh tempat terhadap loyalitas konsumen dalam penelitian ini menunjukkan pihak O'Chicken belum memiliki tempat yang benar-benar strategis, masih kurang nyaman serta kondisi tempat parkir belum kondusif. 


\section{Jurnal Ilmiah Ekonomi dan Bisnis}

Vol. 15. No.1, Maret 2018: 71-77

EISSN : $2442-9813$

ISSN : 1829-9822

Dengan demikian pihak O'Chicken perlu kembali mempertimbangkan lokasi usaha yang lebih strategis, tempat makan yang lebih nyaman serta tempat parker yang lebih kondusif.

Secara Simultan Produk, Harga, Tempat dan Promosi berpengaruh terhadap Loyalitas Konsumen. Hal ini berdasarkan hasil uji $\mathrm{F}$ hitung sebesar 17,189 > F Tabel $(3,29)$ dan signifikansi $\mathrm{F}$ sebesar $0,000<0,05$ maka $\mathrm{H}_{5}$ diterima,. Artinya nilai $\mathrm{F}$ hitung lebih besar dari pada $\mathrm{F}$ tabel, dan nilai signifikan lebih kecil dari 0,05. Hasil ini dapat diartikan bahwa keempat variabel independen produk (X1), harga (X2) promosi (X3) dan tempat (X4) berpengaruh positif dan signifikan secara simultan terhadap loyalitas konsumen.

\section{KESIMPULAN DAN SARAN}

Dari hasil penelitian, dapat ditarik kesimpulan sebagai berikut, secara simultan produk, harga, promosi dan tempat berpengaruh signifikan terhadap loyalitas konsumen. Secara parsial produk dan promosi berpengaruh signifikan terhadap loyalitas konsumen sedangkan harga dan tempat tidak berpengaruh signifikan terhadap loyalitas konsumen.

Penulis memberikan saran sebagai berikut, mengingat harga dan tempat memiliki pengaruh yang lemah terhadap loyalitas konsumen, maka untuk variabel harga, sebaiknya pihak O'Chicken mempertimbangkan kembali harga jual yang di tawarkan kepada konsumen. Sedangkan untuk variabel tempat pihak O'Chicken segera mendapatkan tempat yang benar-benar strategis, meningkatkan kenyaman tempat makannya, serta menyiapkan tempat parkir yang lebih kondusif.

\section{DAFTAR PUSTAKA}

Griffin, Jill. 2009. Customer Loyalty : Menumbuhkan dan Mempertahankan Kesetian Pelanggan, Alih Bahasa oleh Dwi Kartini Yahya.Jakarta : Erlangga

Hurriyati, R. 2010. Bauran Pemasaran dan Loyalitas Konsumen. Bandung: Alfabeta

Kotler, Philip dan Kevin Lane Keller. 2009. Alih Bahasa : Benyamin Molan. Manajemen Pemasaran. Edisi Ketigabelas. Jilid 1 dan 2. Cetakan Keempat. PT. Indeks. Jakarta

Kotler, Philip dan Gary, Armstrong. 2009. Prinsip-prinsip Pemasaran. Jakarta : Erlangga

Kurniawati, Dewi. 2014. Pengaruh Citra Merek dan Kualitas Produk terhadap Kepuasan dan Loyalitas Pelanggan (Studi Pada Pelanggan KFC Cabang Kawi Malang). Jurnal Administrasi Bisnis. Vol:14,No.2. Universitas Brawijaya, Malang.

Kotler, Philip dalam Drs. Danang Sunyoto, SH, SE, MM, 2014, Dasar-dasar Manajemen Pemasaran, Konsep, Strategi dan Kasus, Edisi Ke Tiga, CAPS (Center of Academic Publishing Service)

Lumintang, Andrew A. 2013. "Marketing Mix Pengaruhnya Terhadap Loyalitas Konsumen Sabun Mandi Lifebuoy Di Kota Manado". Jurnal EkonomiManajemen dan Bisnis Akuntansi (EMBA).Vol. 1. No. 3.

Nugroho Setiadi. 2003. Perilaku Konsumen : Konsep dan Implikasi untuk Strategi dan Penelitian Pemasaran. Jakarta : Prenada Medoa 
Oetama, Seanawati. 2011. Analisis Pengaruh Bauran Pemasaran Terhadap Loyalitas Konsumen Pada Motor Honda di Sampit. Jurnal Ilmu Sosial, 3(1): h:40-53

Risyamuka, I.K. 2013. Pengaruh marketing mix terhadap loyalitas pelanggan produk hijau di restoran sari organic

Sugiyono. 2010. Metode Penelitian Bisnis. Bandung: Alfabeta

Tjiptono, Fandy. 2011. Pemasaran Jasa. Bayumedia Publishing. Yogyakarta.

Ubud. Jurnal Fakultas Ekonomi dan Bisnis Universitas Udayana, Bali. September 2013. Hal. 140 - 150. Universitas Sam Ratulangi Manado. Manado.

V.Wiratna Sujarweni, 2015, Metedologi Penelitian, Yogyakarta, Pustaka Baru Press.
Wirasti , Dian Retno. 2010. Pengaruh persepsi kualitas pelayanan , persepsi kewajaran harga dan corporate image terhadap loyalitas dengan kepuasan sebagai variabel mediasi pada layanan after-sales (service -part) toyota nasmoco solobaru. Masters thesis, Universitas Sebelas Maret.

V.Wiratna Sujarweni, 2015, Metedologi Penelitian, Yogyakarta, Pustaka Baru Press.

Yonaldi, Sepris. 2011. "Analisis Pengaruh Variabel Bauran Pemasaran (Marketing Mix) Terhadap Loyalitas Konsumen Produk Minuman Teh Botol Sosro Frestea (StudiKasus Mahasiswa Universitas Andalas Padang)". Jurnal Manajemen dan Kewirausahaan. Volume 2. Nomor 1. Januari 2011. Hal. 79 - 114. Universitas Andalas, Padang. 